\title{
Extubation of the surgically resected airway - a role for remifentanil and propofol infusions
}

\author{
[Extubation de voies aériennes réséquées chirurgicalement - un rôle pour les
}

perfusions de rémifentanil et de propofol]

Palanikumar Saravanan FRCA, ${ }^{*}$ Conor Marnane FRCS ORL-HNS, $\uparrow$ Edmund A.J. Morris FRCA $†$

Purpose: To report the use of propofol and remifentanil infusions to facilitate smooth extubation of a surgically resected airway.

Clinical features: A 19-yr-old man weighing $85 \mathrm{~kg}$ was scheduled for tracheal resection surgery following postintubation tracheal stenosis. He had a relatively long segment $(4 \mathrm{~cm})$ of his trachea resected and anastomosed. Postoperatively, he was sedated and electively ventilated for four days in a chin to chest position by stay sutures. In order to reduce any risk of traumatic disruption to the tracheal anastomosis, we planned to extubate his trachea under light general anesthesia. Attempts to extubate his trachea using propofol and alfentanil infusions failed. We used propofol and remifentanil infusions to achieve a state of sedate cooperation and extubated his trachea with fibreoptic bronchoscope guidance.

Conclusion: Propofol and remifentanil infusions in combination can facilitate successful extubation of the surgically resected airway with high risk of disruption.

Objectif : Présenter l'usage de perfusions de propofol et de rémifentanil pour faciliter l'extubation en douceur de voies aériennes réséquées chirurgicalement.

Éléments cliniques: Un jeune homme de 19 ans, de $85 \mathrm{~kg}$, devait subir une résection trachéale à la suite d'une sténose trachéale post-intubation. Un segment relativement long $(4 \mathrm{~cm})$ de sa trachée $a$ été réséqué et anastomosé. Après l'opération, il a reçu une sédation et une ventilation réglée pendant quatre jours, tête maintenue penchée vers le thorax par des sutures de fixation. Pour réduire le risque de rupture traumatique de l'anastomose trachéale, l'extubation a été réalisée sous anesthésie générale. Les tentatives d'extubation, utilisant des perfusions de propofol et l'alfentanil, ont échoué. Des perfusions de propofol et de rémifen- tanil ont été utilisées pour atteindre un état de calme et de coopération et permettre l'extubation de la trachée avec un fibroscope bronchique comme guide.

Conclusion : Les perfusions combinées de propofol et de rémifentanil peuvent faciliter le succès de l'extubation de voies aériennes réséquées chirurgicalement et à haut risque de rupture.

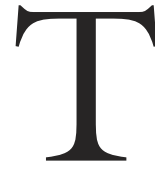
$\mathrm{HE}$ anesthetic management of tracheal resection surgery can be challenging. The need to share the airway with surgical colairway continuity during surgery makes good planning and communication of both anesthetic and surgical technique essential. ${ }^{1,2}$ Extubation of the trachea of a patient who has undergone such surgery can be particularly challenging. Literature on the topic is sparse. We report the use of remifentanil in combination with propofol to facilitate extubation of the anastomosed trachea. The patient provided written consent for publication of this report, in accordance with our institutional guidelines.

\section{Case report}

A 19 -yr-old, $80 \mathrm{~kg}, 165 \mathrm{~cm}$ man was scheduled to undergo tracheal resection surgery at our hospital. His trachea had been intubated for two days following a head injury two months previously. He made a full neurological recovery, but over the weeks following his extubation developed a worsening stenosis of the subglottis and proximal trachea. He had not had any

From the Department of Anesthetics, ${ }^{*}$ Bristol Royal Infirmary, and the Department of ENT, $\uparrow$ Southmead Hospital, Bristol, United Kingdom.

Address correspondence to: Dr. Edmund A.J. Morris, Department of Anesthetics, Southmead Hospital, Bristol, United Kingdom - BS10

5NB. Phone: +44 1179595114 ; Fax: +44 117 9595075; E-mail: edmund.morris@nbt.nhs.uk

Accepted for publication October 28, 2005.

Revision accepted December 16, 2005.

Competing interests: None declared. 


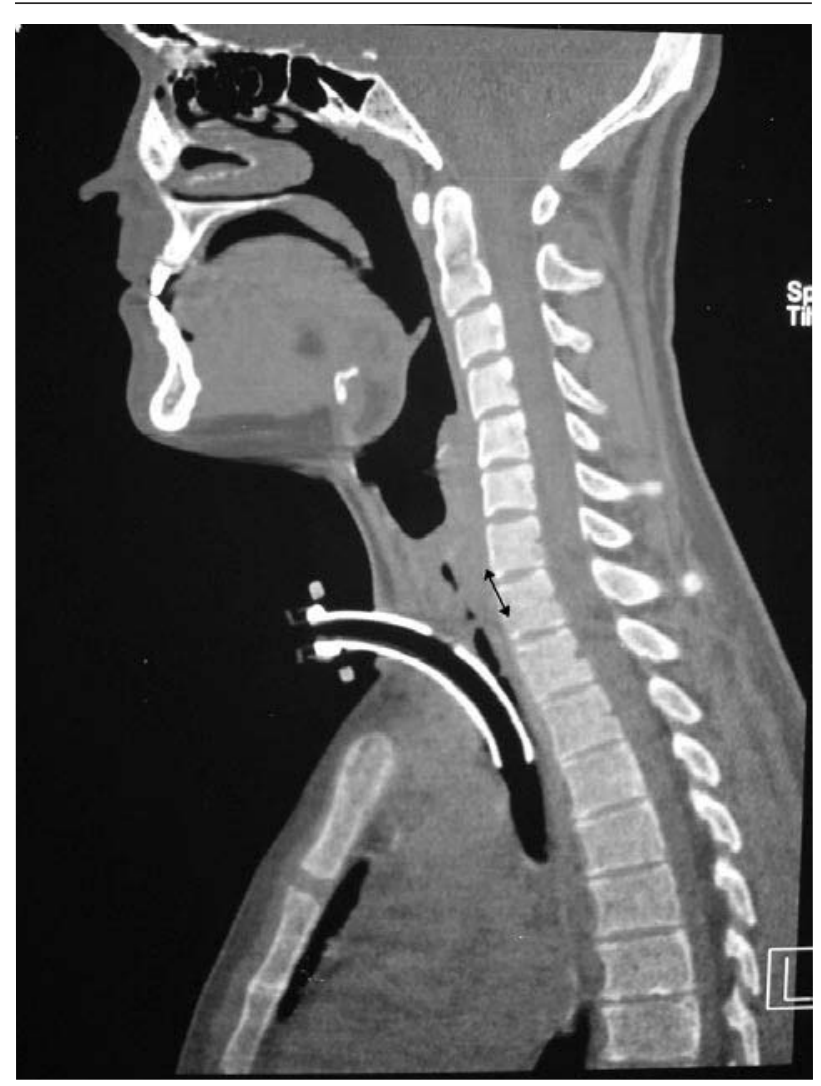

FIGURE I Sagittal plane view of magnetic resonance imaging scan of the neck showing severe tracheal stenosis. The line with double arrow head indicates the length of trachea narrowed.

symptoms of tracheal stenosis prior to his head injury and had no inherited or connective tissue disorders that might have predisposed him to tracheal stenosis. His head injury had been managed initially at a district general hospital, and subsequently at the regional neurosurgical center. No records were available regarding the use of tracheal cuff pressure monitoring during care of the patient. He had undergone endoscopic dilatation of the trachea, but developed severe stridor ten days later and underwent urgent open tracheostomy. Clinical and magnetic resonance imaging findings (Figure 1) were of a tight $(2 \mathrm{~cm}$ long and $<0.5 \mathrm{~cm}$ diameter) circumferential tracheal stenosis $2 \mathrm{~cm}$ above the site of his tracheostomy. As the patient was not keen to have a long-term tracheostomy, he elected to undergo resection of the stenosed segment.

He underwent tracheal resection with end to end anastomosis under general anesthesia. Anesthesia was induced and maintained intravenously with propofol

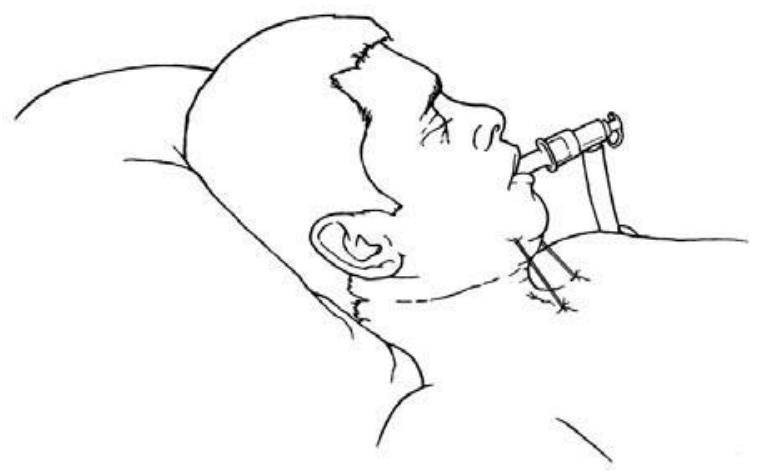

FIGURE 2 Chin to chest position - an artistic view.

and remifentanil infusions with ventilation and oxygenation maintained through the tracheostomy. The trachea was resected from the second to the eighth cartilage (4 cm in total), and at the end of the procedure a sterile $7.5 \mathrm{~mm}$ orotracheal tube was passed across the anastomosis under direct vision with the help of the surgeon. As a relatively long segment of the trachea had been resected, it was felt that the risk of disruption of the anastomosis would be high in the early postoperative period if the patient were to suddenly extend his neck. With this in mind, the surgeon placed stay-sutures between the patient's chin and chest wall to prevent him from extending his neck (Figure 2). He was sedated with propofol and alfentanil infusions and his lungs were ventilated in the intensive care unit. A plan was made to extubate his trachea three days later, but to leave the stay sutures in place for up to a week longer to allow healing of the anastomosis.

In view of the potential airway complications it was decided to extubate his trachea in the operating room under general anesthesia. He was given nebulized lidocaine one hour beforehand to desensitize his trachea. In the operating room he was sedated with alfentanil $2 \mathrm{mg} \cdot \mathrm{hr}^{-1}$ and propofol $300 \mathrm{mg} \cdot \mathrm{hr}^{-1} \mathrm{iv}$. We planned to reduce the rate of infusion of these drugs to achieve a state of wakeful cooperativeness and to extubate his trachea over a fibreoptic bronchoscope, with the neck still held in flexion by the stay sutures. Although we considered using an exchange catheter for extubation, the surgeon was very keen to inspect the anastomosis for patency during extubation. If the 
patient needed immediate tracheal reintubation, we planned to reintroduce the same tracheal tube over the fibreoptic bronchoscope. In the case of supraglottic airway obstruction relating to the presence of the stay sutures, we planned to insert a laryngeal mask airway to maintain upper airway patency. In the event of complete loss of the airway with inability to secure or maintain the airway with a laryngeal mask airway, a surgeon was prepared to perform immediate surgical tracheostomy through the surgical wound.

Several attempts to awaken the patient by reducing the rate of infusion of alfentanil and propofol were unsuccessful. Attempts to change the anesthetic to sevoflurane to establish a spontaneously breathing patient who would be compliant and allow airway assessment also failed: with each attempt he awoke suddenly and with some distress. He had to be immediately restrained and resedated to prevent his sutures from tearing and putting the anastomosis at risk.

We had previously used remifentanil to achieve a state of sedate cooperation in patients undergoing awake fibreoptic intubation and decided to use this opioid to achieve the same effect before attempting to extubate this patient's trachea again. With a background infusion of propofol $\left(100 \mathrm{mg} \cdot \mathrm{hr}^{-1}\right)$, we replaced the alfentanil infusion with a remifentanil infusion at an initial rate of $0.2 \mu \mathrm{g} \cdot \mathrm{kg}^{-1} \cdot \mathrm{min}^{-1}$. Over the next 20 min the remifentanil infusion was decreased to $0.05 \mu \mathrm{g} \cdot \mathrm{kg}^{-1} \cdot \mathrm{min}^{-1}$, by which time the patient was awake, calm, and obeying commands. He was able to communicate that he understood the need to keep his head still. Extubation of the trachea was achieved with the surgeon examining the anastomosis through a fibreoptic endoscope passed through the lumen of the tracheal tube. The patient breathed spontaneously throughout, did not cough, and maintained a patent airway after tracheal extubation without extending his head. Throughout this period his oxygen saturations remained at $99 \%$, heart rate remained between 80 and 90 beats. $\mathrm{min}^{-1}$ and systolic blood pressure was between 140 and $160 \mathrm{mmHg}$. The patient subsequently made a full recovery.

\section{Discussion}

Postintubation tracheal stenosis is the most common indication for tracheal resection surgery in spite of the use of high volume, low pressure cuffs on endotracheal tubes. ${ }^{3}$ Therapeutic options include balloon dilatation, stenting and laser excision of the lesion, as well as tracheal resection surgery. ${ }^{4-6}$ If dilatation or stenting are used, multiple operations may be necessary. Laser excision can cause scar tissue to form during healing and may worsen the stenosis. In this patient, because of the tight stenosis which developed relatively rapidly over a period of several days, it was felt that permanent tracheostomy or tracheal resection were the only realistic options.

Intraoperative anesthetic management of tracheal resection is well described. ${ }^{1,2}$ Following tracheal resection with primary anastomosis, the trachea is subjected to tension. Various releasing maneuvers have been described to increase the length of trachea that can be safely resected to reduce the tension. ${ }^{7}$ Tracheal transplants have also been tried. ${ }^{8}$ In the postoperative period the neck is usually kept under flexion to reduce the tension. This is normally achieved by placing sutures between the chin and the chest. Alternatively, neck flexion can be achieved by placing external splints. ${ }^{9}$ Despite these precautions, anastomotic complications still occur in $9 \%$ of patients undergoing this type of surgery; risk factors for complication include a resection of $>4 \mathrm{~cm}$ of trachea and the need for tracheostomy before the operation. ${ }^{3}$ As our patient had these two risk factors he was considered to be at relatively high risk of developing anastomotic complications. Though poor vascularity of the tissues and superadded infection are described as the common reasons for dehiscence of a tracheal anastomosis, the presence of the inflated cuff of the tracheal tube, coughing or bucking and any trauma during extubation or reintubation can potentially cause tracheal rupture. Emergency intubation is a known cause for tracheal injury even in the normal trachea. ${ }^{10}$

Extubation of the trachea is found to be associated with more complications than intubation in a normal trachea. ${ }^{11}$ The American Society of Anesthesiologists Task Force on Difficult Airway Management has published recommendations for the management of extubation in a difficult airway. ${ }^{12}$ An algorithm for extubation of the difficult airway is also available in the review by Miller et al. ${ }^{13}$ These algorithms describe the airway equipment available to facilitate extubation, and the advantages and limits of each. The guidelines contain no specific advice for extubation after airway surgery and do not suggest the use of $i$, anesthetic agents such as propofol and remifentanil in such situations.

Traditional teaching suggests that patients with a difficult airway should be fully awake and cooperative before extubation, although there are certain circumstances in airway surgery where a decision is made to perform extubation under deep inhalational anesthesia to allow smoother awakening. ${ }^{14}$ Such "deep extubation" can be used, for example, to avoid extubation laryngospasm or to reduce coughing and straining after airway or other head and neck surgery, particu- 
larly in patients in whom reintubation would not be particularly difficult. Sevoflurane and desflurane have been found to be useful for deep extubation. ${ }^{15,16}$ However, an increased incidence of airway obstruction has been reported with concentrations of more than one minimum alveolar concentration. ${ }^{16}$ We tried to use sevoflurane not to perform deep extubation but to provide a compliant patient prior to awake extubation: as we have reported, this was not possible. Nevertheless, inhalational agents can be useful for planned extubation under appropriate circumstances.

Propofol and remifentanil either in combination or alone have been used to provide or supplement anesthesia during awake fibreoptic intubation or airway surgery. ${ }^{17-19}$ Both of these drugs can suppress the cardiovascular response during emergence. ${ }^{20,21} \mathrm{~A}$ continuous infusion of remifentanil between 0.05 to $0.075 \mu \mathrm{g} \cdot \mathrm{kg}^{-1} \cdot \mathrm{min}^{-1}$ has been demonstrated to provide good intubating conditions. ${ }^{18,19}$ When remifentanil was used alone, a high incidence of recall was reported. ${ }^{18}$ However, neither propofol nor remifentanil have been described to facilitate tracheal extubation after airway surgery.

Several airway adjuncts can be used to aid the safe extubation of the difficult airway such as Cook's exchange catheter, the endotracheal ventilation catheter and the fibreoptic bronchoscope. ${ }^{12,13}$ We used the fibreoptic bronchoscope because of the added advantage (and the surgeon's request) that the airway could be assessed during extubation. ${ }^{22,23}$ In the event of failed extubation due to the fixed flexion of the patient's neck we planned to insert a laryngeal mask airway. The laryngeal mask airway has been shown to be useful in securing the airway and maintaining anesthesia whilst the airway is further evaluated and during the creation of a surgical airway should this be necessary. ${ }^{24,25}$ Should control of the airway have been lost below the level of the glottis our surgeon would have performed immediate tracheostomy through the site of the previous surgery.

This case demonstrates that infusion of remifentanil in association with low dose propofol can facilitate extubation of the trachea following airway surgery, providing wakeful compliance in a patient before the tracheal tube is removed. Patients who have undergone airway resection surgery present a particular challenge to the anesthesiologist, and we believe this anesthetic approach should be considered when performing extubation in such patients.

\section{References}

1 Magnusson L, Lang FJ, Monnier P, Ravussin P. Anaesthesia for tracheal resection: report of 17 cases.
Can J Anaesth 1997; 44: 1282-5.

2 Pinsonneault C, Fortier J, Donati F. Tracheal resection and reconstruction. Can J Anesth 1999; 46: 439-55.

3 Wright CD, Grillo HC, Wain JC, et al. Anastomotic complications after tracheal resection: prognostic factors and management. J Thorac Cardiovasc Surg 2004; 128: 731-9.

4 Grillo HC, Donahue DM. Postintubation tracheal stenosis. Chest Surg Clin N Am 1996; 6: 725-31.

5 Noppen M, Schlesser M, Meysman M, D'Haese J, Peche $R$, Vincken $W$. Bronchoscopic balloon dilatation in the combined management of postintubation stenosis of the trachea in adults. Chest 1997; 112: 1136-40.

6 Nesbitt JC, Carrasco H. Expandable stents. Chest Surg Clin N Am 1996; 6: 305-28.

7 Rosen FS, Pou AM, Buford WL. Tracheal resection with primary anastomosis in cadavers: the effects of releasing maneuvers and length of tracheal resection on tension. Ann Otol Rhinol Laryngol 2003; 112: 869-76.

8 Yokomise H, Inui $K$, Wada $H$, Ueda M, Hitomi S, Itoh $H$. Split transplantation of the trachea: a new operative procedure for extended tracheal resection. J Thorac Cardiovasc Surg 1996; 112: 314-8.

9 Mueller DK, Becker J, Schell SK, Karamchandani KM, Munns JR, Jaquet B. An alternative method of neck flexion after tracheal resection. Ann Thorac Surg 2004; 78: 720-1.

10 Chen EH, Logman ZM, Glass PS, Bilfinger TV. A case of tracheal injury after emergent endotracheal intubation: a review of the literature and causalities. Anesth Analg 2001; 93: 1270-1.

11 Asai T, Koga K, Vaughan RS. Respiratory complications associated with tracheal intubation and extubation. Br J Anaesth 1998; 80: 767-75.

12 Caplan RA, Benumof JL, Berry FA, et al. Practice guidelines for management of the difficult airway. A report by the American Society of Anesthesiologists Task Force on Management of the Difficult Airway. Anesthesiology 1993; 78: 597-602.

13 Miller KA, Harkin CP, Bailey PL. Postoperative tracheal extubation. Anesth Analg 1995; 80: 149-72.

14 Daley MD, Norman PH, Coveler LA. Tracheal extubation of adult surgical patients while deeply anesthetized: a survey of United States anesthesiologists. J Clin Anesth 1999; 11: 445-52.

15 Valley RD, Freid EB, Bailey AG, et al. Tracheal extubation of deeply anesthetized pediatric patients: a comparison of desflurane and sevoflurane. Anesth Analg 2003; 96: 1320-4.

16 Inomata S, Yaguchi $\Upsilon$, Taguchi M, Toyooka H. Endtidal sevoflurane concentration for tracheal extubation (MACEX) in adults: comparison with isoflurane. Br J Anaesth 1999; 82: 852-6. 
17 Donaldson AB, Meyer-Witting $M$, Roux A. Awake fibreoptic intubation under remifentanil and propofol target-controlled infusion. Anaesth Intensive Care 2002; 30: $93-5$.

18 Puchner W, Egger P, Pubringer F, Lockinger A, Obwegeser J, Gombotz H. Evaluation of remifentanil as single drug for awake fiberoptic intubation. Acta Anaesthesiol Scand 2002; 46: 350-4.

19 Machata AM, Gonano C, Holzer A, et al. Awake nasotracheal fiberoptic intubation: patient comfort, intubating conditions, and hemodynamic stability during conscious sedation with remifentanil. Anesth Analg 2003; 97: 904-8.

20 Kulkarni A, Price G, Saxena M, Skowronski G. Difficult extubation: calming the sympathetic storm. Anaesth Intensive Care 2004; 32: 413-6.

21 Shajar MA, Thompson JP, Hall AP, Leslie NA, Fox AJ. Effect of remifentanil bolus dose on the cardiovascular response to emergence from anaesthesia and tracheal extubation. Br J Anaesth 1999; 83: 654-6.

22 Nakagawa H, Komatsu R, Hayashi K, Isa K, Tanaka $\Upsilon$. Fiberoptic evaluation of the difficult extubation. Anesthesiology 1995; 82: 785-6.

23 Popat MT, Dravid RM, Watt-Smith SR. Use of the flexible intubating fibrescope for tracheal re-intubation in a patient with difficult extubation. Anaesthesia 1999; 54: 359-61.

24 Asai T. Use of the laryngeal mask after tracheal extubation (Letter). Can J Anesth 1999; 46: 997-8.

25 Dob DP, Shannon CN, Bailey PM. Efficacy and safety of the laryngeal mask airway vs Guedel airway following tracheal extubation. Can J Anesth 1999; 46: 179-81. 